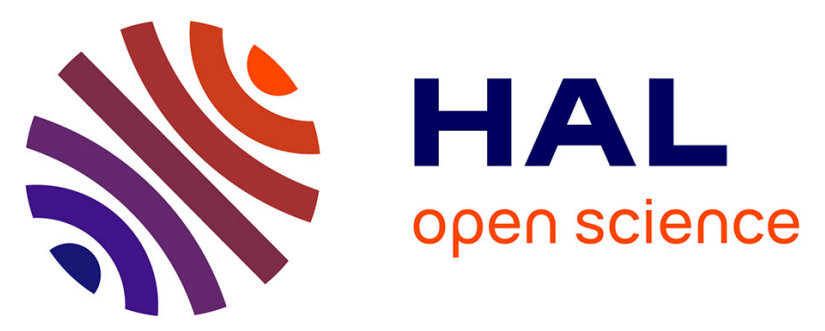

\title{
Boiling curves in relation to quenching of a high temperature moving surface with liquid jet impingement
}

Michel Gradeck, Arsène Kouachi, Fabien Volle, Denis Maillet, Michel

Lebouché, Jean-Luc Borean

\section{- To cite this version:}

Michel Gradeck, Arsène Kouachi, Fabien Volle, Denis Maillet, Michel Lebouché, et al.. Boiling curves in relation to quenching of a high temperature moving surface with liquid jet impingement. International Journal of Heat and Mass Transfer, 2009, 52 (5-6), pp.1094-1104. 10.1016/j.ijheatmasstransfer.2008.09.015 . hal-01580004

\section{HAL Id: hal-01580004 \\ https://hal.univ-lorraine.fr/hal-01580004}

Submitted on 31 Aug 2017

HAL is a multi-disciplinary open access archive for the deposit and dissemination of scientific research documents, whether they are published or not. The documents may come from teaching and research institutions in France or abroad, or from public or private research centers.
L'archive ouverte pluridisciplinaire HAL, est destinée au dépôt et à la diffusion de documents scientifiques de niveau recherche, publiés ou non, émanant des établissements d'enseignement et de recherche français ou étrangers, des laboratoires publics ou privés. 


\title{
BOILING CURVES IN RELATION TO QUENCHING OF A HIGH TEMPERATURE MOVING SURFACE WITH LIQUID JET IMPINGEMENT
}

\author{
M Gradeck ${ }^{1}$, A Kouachi ${ }^{1}$, M Lebouché ${ }^{1}$, F Volle ${ }^{1}$, D. Maillet ${ }^{1}$, JL Borean ${ }^{2}$ \\ ${ }^{1}$ LEMTA Nancy University, CNRS, Vandoeuvre-lès-Nancy, France \\ ${ }^{2}$ ARCELOR Research, Maizières-lès-Metz, France \\ corresponding author : michel.gradeck@ensem.inpl-nancy.fr
}

\begin{abstract}
Experimental investigations have been conducted for quenching of a hot rotating cylinder with initial temperature of about $500-600^{\circ} \mathrm{C}$ by a subcooled planar water jet. An original experimental device allowing the estimation of the local boiling curves in the case of a static surface and of a moving surface has been designed. Heat fluxes were measured on both side of the axis of the jet until a reduced distance $\mathrm{x} / \ell$ of 18 , in a range of subcooling from 10 to $83 \mathrm{~K}$, for a jet velocity from 0,8 to $1,2 \mathrm{~m} / \mathrm{s}$ and for a velocity flow-surface ratio $\left(u_{s} / u_{j}\right)$ from 0.5 to 1.25 . In the case of static surface, the measurements confirmed the existence of a "shoulder of flux" in the stagnation zone of the jet. In the case of a moving surface, the maximum of heat transfer (for a given regime) is moving during the cooling time from downstream (film boiling regime) to upstream (forced convection).
\end{abstract}

Keywords : quenching, boiling curve, inverse heat conduction problem, impinging jet, moving surface

\section{Nomenclature}

CHF critical heat flux

d nozzle to plate spacing

$h_{l g} \quad$ latent heat of phase change $(\mathrm{kJ} / \mathrm{kg})$

$\ell \quad$ width of the nozzle (m)

$L \quad$ width of the strip or cylinder (m)

MHF maximum of heat transfer

$P \quad$ power supply (W)

$T \quad$ temperature $\left({ }^{\circ} \mathrm{C}\right)$ 
$\Delta T_{\text {sat }} \quad$ superheat $(\mathrm{K})\left(\Delta T_{s a t}=T_{w}-T_{s a t}\right)$

$\Delta T_{s u b} \quad$ subcooling $(\mathrm{K})\left(\Delta T_{s u b}=T_{s a t}-T_{l}\right)$

$u \quad$ velocity $(\mathrm{m} / \mathrm{s})$

$u^{*} \quad$ velocity ratio $\left(u_{S} / u_{j}\right)$

$\omega \quad$ angular velocity $(\mathrm{rad} / \mathrm{s})$

$x \quad$ distance from the jet axis (m)

$x^{*} \quad$ dimensionless distance

\section{Subscripts}

g gas

$j \quad$ jet

$l \quad$ liquid

$S \quad$ strip, surface

sat saturation

sub subcooled

w wall 


\section{Introduction}

Generally, quenching is needed for ensuring very high cooling rate. In nuclear plants, quenching of the reactor core is a safety procedure in case of a loss of primary refrigerant accident. So it is necessary to predict accurately the rate of cooling of the fuel elements. In manufacturing industries, quenching can be used for cooling moulds (glass-maker industry) or controlling the structure of the steel alloys. Structure and thus mechanical properties of steel alloys are conditioned by the cooling rate of the product. It is thus of primary importance to well control this cooling rate and its homogeneity to obtain steels with good and homogeneous mechanical properties. This cooling is usually ensured by quenching of the hot moving strip by many subcooled water jets. According to the quality wished, rates of cooling must vary between $15 \mathrm{~K} / \mathrm{s}$ and $1000 \mathrm{~K} / \mathrm{s}$. Obviously, this kinetics depends on the various boiling regimes met during transient cooling: film boiling, transition boiling, critical heat flux (CHF) and nucleate boiling. Although this type of cooling process has been still widely studied, the full heat transfer mechanisms are not well understood and no boiling curves are available for a hot moving surface. This knowledge is of great importance for steel making industry. After being rolled, the steel strip temperature is about $800-1000^{\circ} \mathrm{C}$ and must be cooled with impinging water jets. Since the surface to be cooled is moving, the estimation of the heat transfer mechanisms are misunderstood. The main reasons are that boiling experiments with high temperature are very difficult to achieve ; making experiments with a moving surface in order to be realistic with respect to the industrial conditions is another challenge. So the estimation of heat transfer (boiling curves) occurring on a very hot moving surface needs the design of a special setup.

A particular shape of the boiling curve can be observed in the transition regime in the case of impinging jet on a hot plate (figure 1). Many studies led to the estimation of the boiling curve from transient experiments. Ishigai et al. [1], Ochi [2] and Hall [3] gave a report on the existence of a «shoulder of flux » beneath the jet (transition boiling regime) and highlighted the existence of 
several regimes on hot surface to be cooled at a given time. Ishigai et al. [1] have carried out experiments in jet impingement configurations for wall temperature up to $1200 \mathrm{~K}$ and for jet subcoolings up to $55 \mathrm{~K}$. They observed that the boiling curves are moved towards higher overheats and heat fluxes when subcooling increased. The "shoulder of flux" is visible only for subcooling greater than $15 \mathrm{~K}$ and its width increases when subcooling increases. For $\Delta \mathrm{T}_{\text {sub }}$ greater than $55 \mathrm{~K}$, they have not observed film boiling regime within the range of their experiments $(u j \sim 2 \mathrm{~m} / \mathrm{s})$. The authors also reported on the effect of the jet velocity. For weak subcooling, the heat flux increased when jet velocity grew. Ishigai et al. [1] also reported that the minimum heat flux increased with the jet velocity and subcooling ; they proposed a correlation for the Leidenfrost point.

Ochi et al. [2] measured boiling curves during transient cooling of a steel plate $\left(50 \times 210 \mathrm{~mm}^{2}\right.$ and thickness $2 \mathrm{~mm}$ ) impinging with a circular water jet. The plate was heated up to $1100^{\circ} \mathrm{C}$ then the heating was stopped just before being quenched by a subcooled water jet (subcooling between 5 and $80 \mathrm{~K}$, for a velocity jet from 2 to $7 \mathrm{~m} / \mathrm{s}$ ). Five thermocouples (diameter $50 \mu \mathrm{m}$ ) left again with interval of $6 \mathrm{~mm}$ measure the instantaneous near wall temperature. The authors have numerically estimated the heat flux and the wall temperature by solving the axisymmetrical heat conduction equation. The boiling curves measured by Ochi [2] show the same typical characteristic than those reported in the works of Ishigai et al. [1]. Flux decreases with the diameter of the jet because the radial gradient of velocity becomes weaker on impacted surface. It is very difficult to determine a "shoulder of flux" from transient experiments as shows in the work of Hall et al. [3] who have measured local boiling curves for a jet velocity of $3 \mathrm{~m} / \mathrm{s}$ with subcooling of $75 \mathrm{~K}$. The diameter of the jet is $5.1 \mathrm{~mm}$ and the distance from the exit to the wall is $100 \mathrm{~mm}$. The plate is initially heated up to $650^{\circ} \mathrm{C}$.flux decrease with the distance to the stagnation line.

Wolf et al. [4] presented some experimental results for a free surface impinging jet on a hot surface. They provided valuable data of local boiling curves at several streamwise distance from the stagnation line. 
Robidou et al. [5] carried out experiments under steady-state conditions. They used a temperature controlled system in order to measure the entire boiling curve under steady-state conditions. Their set-up enable measurements at wall temperature up to $700^{\circ} \mathrm{C}$. The local boiling curves are estimated from wall temperature inversion as a function of the distance from the stagnation line. They investigated both free jets and immersed jets for various jet subcooling and jet velocity. They noticed no influence of jet velocity, subcooling on the heat flux in the parallel flow region (in the case of an impinging jet). CHF decreases with the distance from the stagnation line but increases with higher jet velocities and subcooling. Moreover, they outlined a particular transition boiling regime at the stagnation line extended on a broad beach of wall overheating. This phenomenon can be related to the break up of the vapour layer beneath the jet that conduced to wetting of the wall. Hence, as the vapour layer cannot be stabilized, the heat flux increased again and the Leidenfrost temperature is widely increased. A complete description of this particular regime and a modelling of this phenomena called "shoulder of flux" is reported in an article of Seiler et al. [6]. According to the study of Seiler et al. [6], the « shoulder of flux » should be a consequence of a time dependent phenomenon during which the amount of liquid that reaches the wall is heated and then evacuated because of phase change. Outside the stagnation zone, the boiling curves seems to be similar to those obtained in pool boiling conditions.

On Figure 2, a scheme of a cooling system at the very end of the rolling process is represented. As the cooling is done with circular jet on the upward face and generally with sprays on the downward face, the cooling rate can be very different. On the upward face, we can observe dark zones on the photo corresponding to the zones beneath each jet (quick cooling rate) and red zones which correspond to temperatures over $700^{\circ} \mathrm{C}$ in the external zone of the jet (low cooling rate) ; that is to say that the heat transfer at the wall is very heterogeneous because of the very complex flow due to interaction between impinging jets and the moving wall and interactions betweens the jets as well. 
Simplifying the problem (without considering the phase change), for a free surface jet impinging a static surface, we can distinguish three main zones according to Watson [7]: the impingement zone beneath the water jet known as the stagnation zone, the development zone (parallel flow region) and finally the hydraulic jump. For each zone, we expect to find various heat flux or heat transfer coefficient because of the strong influence of the velocity field. In real conditions, jets can act on each other, the strip moves, and as the wall temperature can be over the saturation temperature of water, boiling can occur. So, the real problem is really complex and that is why the basic mechanisms of this cooling process are still an open problem.

Our first goal is to complete the database for impinging water jet on hot surfaces but for moving ones. To achieve that, we built a set-up which can perform experiments in the case of a hot moving surface (rotating cylinder). The results presented here have been obtained in the configuration of an impinging planar water jet on a static hot cylinder (initial temperature of about $600^{\circ} \mathrm{C}$ ) for a various range of operating conditions (subcooling temperature of the jet, jet velocity) and for a rotating hot cylinder in order to simulate conditions which are not far from the real cooling system. Particular attention was paid to boiling conditions since the two-phase cooling of hot surfaces is a fundamental task in steel making industry. All the results presented here are part of the experiences made in our team research during the $\mathrm{PhD}$ thesis of $\mathrm{A}$. Kouachi [8]

\section{Experimental set up}

The set-up which has been used in this study is schematically outlined in Figure 3. The boiling vessel contains the jet (5) and the hot revolving cylinder (7). The external diameter of the cylinder is equal to $175 \mathrm{~mm}$ and the internal equals $100 \mathrm{~mm}$ (length $=200 \mathrm{~mm}$ ). The heating is ensured by three electrical wires which are wounded on another cylinder which itself is adjusted with the external cylinder. A heating with constant heat flux $(P)$ is thus ensured on the internal radius. Resistances can dissipate $2000 \mathrm{~W}$ each one (10). Two cooled stainless steel flasks (6) are laid out on both sides of the main cylinder in order to insulate the heated cylinder from the revolving contacts and to 
center it in order to avoid the unbalances. An automatic device allows the system to dilate without generating additional constraints with the device. 24 thermocouples ( $\mathrm{N}$ type) are inserted on the external diameter; they are placed in bleedings and a coating is deposited. The electrical output is provided to resistances by means of revolving contacts (8). The signals (9) of the thermocouples are then also transmitted to a computer (11) to be recorded via revolving contacts (8).

The test fluid (water) is firstly heated at the subcooled temperature in a vessel (1) and circulates firstly in a primary circuit. Then, the flow rate is adjusted using a pump (2) and an electromagnetic flowmeter (3). When all the initial parameters are adjusted, the electromagnetic sluice gate (4) is open and the cooling of the cylinder can begin. The jet has an outlet cross sectional area of $180 \times 4 \mathrm{~mm}^{2}$. The water jet outlet is located at a distance $d$ from the hot cylinder and impinges the higher line of the cylinder. This distance can be adjusted.

\section{Data reduction}

\subsection{Direct problem}

We consider internal transient conduction within a finite circular cylinder. Assuming that the transverse conduction is negligible, we will only consider a two-dimensional problem. The basic equations are thus the followings :

$$
\begin{aligned}
& \rho C_{p} \frac{\partial T}{\partial t}=\frac{1}{r} \frac{\partial}{\partial r}\left(r k \frac{\partial T}{\partial r}\right)+\frac{1}{r} \frac{\partial}{\partial \theta}\left(\frac{k}{r} \frac{\partial T}{\partial \theta}\right) \\
& -k \frac{\partial T}{\partial r}=\dot{q}_{1} \text { for } r=R_{1}\left(\dot{q}_{1}=P / 2 \pi R_{1} L\right) \\
& -k \frac{\partial T}{\partial r}=\dot{q}_{2}(\theta, t) \text { for } r=R_{2} \\
& T(r, \theta, t)=T_{t=0}
\end{aligned}
$$

$R_{1}$ is the internal radius of the heated cylinder and $R_{2}$ is its external radius where boiling occurs. 
$\dot{q}_{1}$ is the heat flux density supplied by the three electrical resistances which is assumed to be without losses due to the transverse conduction ; $\dot{q}_{2}(\theta, t)$ is the extracted flux. $T_{t=0}$ is the initial temperature. An analytical solution can be developed assuming that the thermophysical properties of the material are constant on the temperature range of the experiments. This solution, based on Laplace and Fourier transforms, is obtained by solving the heat equation and is explicitly given using series expansions and modified Bessel functions. The temperature (in the Fourier and Laplace spaces) can be expressed as a linear relation with the unknown condition $\dot{q}_{2}$. The full description of the solution is developed in reports by Volle et al. [9-10].

\subsection{Inverse problem}

The measured temperature signal is transformed in the Fourier (angular transform) and Laplace (time transform) spaces. These transforms corresponds to a Singular Value Decomposition [11,12] but they are not sufficient to stabilize the solution of the inverse problem because the temperature signal is noised and because the measurements are done in a remote position (not directly at the wall). So Beck's future time steps [13] have been implemented in our inverse code to stabilize the solution. A good comparison is obtained between the heat flux estimated through this semianalytical solution and those estimated through the method developed by Blanc et al. [14]

The great advantage of the analytical method that we used for the heat fluxes estimation is the weak time of treatment. In our cooling experiments, the total time of the experiment can be up to ten minutes so depending on the frequency of the recording, the data file could exceed more than six hundred thousand points.

\subsection{Building of the local boiling curves}

In the case of a static surface and as the solution of the inverse problem is obtained in the reference frame of the cylinder, the building of the local boiling curves is easy. Each wall temperature corresponds to one estimated heat flux at one location. In the case of a rotating cylinder, it is more 
difficult because the reference frame of the cylinder is moving compared to the reference frame of the jet. But a position encoder enables us to know at each time where are located the temperature sensors compared to the position of the jet. So the building of the transient local boiling curves are still possible.

\section{Results and discussion}

\section{1 case of a static cylinder $(\omega=0 \mathrm{rad} / \mathrm{s})$}

\subsubsection{Time evolution of the temperature and heat fluxes}

The cooling experiments are all made under transient conditions. The temperature of the cylinder is firstly stabilized to a value close to $600^{\circ} \mathrm{C}$; then it is cooled by a subcooled planar water jet. Figure 3 shows the time evolutions of the temperatures measured by thermocouples located at a point beneath the jet axis (stagnation line, $\left.x^{*}=x / \ell=0\right)$ and at a reduce distance $x^{*}=9.15(x=36.6 \mathrm{~mm}$ in the parallel flow zone) and the time evolutions of the estimated heat flux. This experiment has been done with a jet velocity of $1,2 \mathrm{~m} / \mathrm{s}$, a subcooling of $15 \mathrm{~K}$ and a nozzle to plate distance of $50 \mathrm{~mm}$. In the case of the stagnation point, the wall temperature falls down in the first times which correspond to the initial quenching (establishment of a vapour layer). At the same time, the heat flux will rise and stabilize at a weak value (Film boiling corresponding to point A). During film boiling regime (part $\mathrm{AB}$ ), heat transfer remains weak and nearly constant (thermal resistance of the vapour film). Then the temperature decreases again in a spectacular way because the Leidenfrost point has been reached at point $\mathrm{B}$ (transition boiling). The heat flux remains very high on a large range of temperature; this boiling regime can be compared to a transition boiling regime until $\mathrm{CHF}$ at point C. After that, the temperature will decrease again, during the nucleate boiling regime. After the end of boiling at point $\mathrm{D}$, the wall temperature still decreases but according to weaker kinetics (forced convection).

In the parallel flow region, the evolution of the temperature is quite different; the temperature still decreases but much more slowly; that is to say that at the same time, boiling regimes are very 
different compared to those occurring in the stagnation region. A wetting front is displacing slowly from the stagnation zone to the parallel flow region as describe by Mozumber et al. [15]. In our case, Leidenfrost point $\mathrm{B}$ is reached after 30 seconds. But these temperature evolutions must be discussed in reference with the corresponding boiling curves (figure 4).

\subsection{2 local boiling curves in the case of a static cylinder ( $\omega=0 \mathrm{rad} / \mathrm{s})$.}

At the impact point, initial quenching is observed approximately until 500K (see fig.5) and during 1.5s (see fig. 4). This zone results from the first wetting by the water followed by a setting in thermal balance with the hot surface. In the film boiling mode $(\mathrm{AB})$, heat flux extracted varies slightly, it remains about $0.5 \mathrm{MW} / \mathrm{m}^{2}$. The wall is insulated by a vapour film. The wetting of the wall lead to a sharp increase of heat flux; transition boiling takes place. It is characterized by the appearance of a plate of flux (or shoulder of flux) which extends between approximately $\Delta T_{\text {sat }}=$ 430 and $\Delta T_{\text {sat }}=250 \mathrm{~K}$. This plate appears after $2,7 \mathrm{~s}$ of cooling and stops after $3,7 \mathrm{~s}(\mathrm{BC})$. According to Seiler et al. [6], this "shoulder of flux" vanishes when the diameter of the bubbles is of the order of the critical diameter of fragmentation; extracted heat flux increases then until CHF. Then nucleate boiling regime is characterized by a significant reduction of flux values when overheating decreases. The limit of boiling is characterized successively by a decrease and then a growth of overheating (establishment and destruction of the thermal boundary layer). The forced convection regime is characterized by a linear evolution of the heat flux extracted with overheating at the wall.

Boiling curves are thus very different in the two regions (Figure 4). At the stagnation line, the heat flux is always greater than heat flux estimated in the parallel flow region; hence, as the distance from the stagnation line increases, the effect of the jet velocity will decrease because of the spread out of the jet and the development of the boundary layers. Thus, the critical heat flux (CHF) decreases as the distance from the stagnation line increases. For the given test conditions $\left(\Delta T_{\text {sub }}=15 \mathrm{~K}-u_{j}=1.2 \mathrm{~m} / \mathrm{s}-d=50 \mathrm{~mm}\right)$, the $\mathrm{CHF}$ at the stagnation line is two times greater than the 
one measured in the parallel flow region. After CHF, at the stagnation line, the heat flux shape is very unstable and its values remain very high $\left(\sim 2.5 \mathrm{MW} / \mathrm{m}^{2}\right)$. This result can be compared to the "shoulder of flux" observed by Ishigai et al. [1], Ochi et al. [2] and very well described by Robidou et al. [5]. The boiling curve obtained at the stagnation is consistent with Robidou's one in similarly conditions $\left(\Delta T_{\text {sub }}=15 \mathrm{~K}, u_{j}=0.8 \mathrm{~m} / \mathrm{s}\right)$.In the parallel flow region, the heat flux value decreases to a minimum; it is possible that this minimum corresponds to a dry out of the surface probably because of its curvature: a stable film boiling regime cannot take place. However, if we compare our results to the data of Robidou et al. [5] obtained in similar conditions, the values of characteristic points of our boiling curves are close to those observed by these authors [5]. Equation (3) for CHF heat flux given by Miyasaka et al. [16] which is valid for the stagnation region for impinging planar jets of water gives a CHF value of about $3.17 \mathrm{MW} / \mathrm{m}^{2}$. The thermophysical values used for this calculation are reported in Table 1.

$q^{\prime \prime}{ }_{C H F}=\left(1+0.86 u_{j}^{0.38}\right)\left\{0.16 \rho_{g} h_{\mathrm{lg}}\left[\frac{\sigma\left(\rho_{l}-\rho_{g}\right)}{\rho_{g}^{2}}\right]^{1 / 4}\right\}\left(1+0.112\left(\frac{\rho_{l}}{\rho_{g}}\right)^{0.8}\left(\frac{c_{p l} \Delta T_{\text {sub }}}{h_{\mathrm{lg}}}\right)\right)$

The cooling rate is also affected by the subcooling of the liquid jet. In a recent paper, Gradeck et al. [18] have made some measurements of the temperature at the stagnation line for a jet velocity of 1.2 $\mathrm{m} / \mathrm{s}$, and different subcooling $(15 \mathrm{~K}, 25 \mathrm{~K}$ and $34 \mathrm{~K})$. In these subcooling cases, equation (3) gives results which are close to our estimated values : $3.17 \mathrm{MW} / \mathrm{m}^{2}$ for $\Delta T_{\text {sub }}=15 \mathrm{~K}, 4.33 \mathrm{MW} / \mathrm{m}^{2}$ for $\Delta T_{\text {sub }}=25 \mathrm{~K}$ and $5.38 \mathrm{MW} / \mathrm{m}^{2}$ for $\Delta T_{\text {sub }}=34 \mathrm{~K}$. In nucleate boiling regime, the subcooling has no influence as it has always been observed in other studies. On the other hand, the influence of the subcooling is very marked on the CHF as it has been already observed by Miyasaka et al. [15] and Robidou et al. [5].

\section{2 rotating cylinder $(\omega \neq 0 \mathrm{rad} / \mathrm{s})$}


In the case of a moving surface impinged by a free water jet, the flow field will be deeply modified as it has been experienced by Gradeck et al. [17]. Phase change will also locally modify the flow field, but how deep is the influence of the flow field modification on heat transfer coefficient, that is a great question and we are able to give some answers. The first obvious effect shown on the photos of figure 6 is the displacement of the position of the hydraulic jump as well as the modification of its radius.

\subsubsection{Time Evolution of measured temperatures and estimated fluxes}

In rotating cases, the temperature sensors give an information which must be post treated because we want to give an overview of the heat transfer in the jet reference frame and not in the moving reference frame of the sensor. So, when the hot rotating cylinder is quenched by the jet, the sensor is located in two main zones : a zone influenced by the water jet impingement where the cooling is efficient and a zone where the jet has no influence anymore because of the curvature of the cylinder ("dry" zone). When the sensor is in the first zone, the temperature will strongly decrease and when it is in the second zone, the temperature will rise again because of internal conduction effects. If we focus on figure 7 which represent the time evolution of the temperature $\left(\Delta T_{s u b}=34 \mathrm{~K}-u^{*}=1.25-d=\right.$ $50 \mathrm{~mm}$ ), we first observe that the full time for cooling in the case of a moving surface is much more greater than the full time for cooling in the case of a static surface (considering only the temperature sensor area). The temperature measurement seems to be noisy but it is not the case; it is simply the effect of the rotation of the cylinder (see fig. 8 which is a zoom of fig. 7).

Some details of the time evolution of the temperature are shown on Figures 8. Some characteristics crossing points have been marked : the stagnation line $\left(x^{*}=0\right)$ corresponds to the crossing of the thermocouple beneath the jet axis; other points which correspond to the downstream zone $(x *>0)$ and the upstream zone $\left(x^{*}<0\right)$ have been marked. During the cooling time, the "cooling zone" always evolves ; at the quenching time (beginning of the experiment, figure 8a), the temperature begins to fall down only when the thermocouple is crossing the jet axis $\left(x^{*}=0\right)$; after that, the 
temperature rises again at the point $x^{*}=13.75$. During the film boiling regime (fig. $8 \mathrm{~b}$ ) and the transition boiling (fig. 8c), the cooling zone evolves a little bit and until the point $x^{*}=17.2$. After CHF, the cooling zone is extending and will progressively cover the upstream zone (fig. 8d, nucleate boiling and fig. 8e, forced convection). So according to figures 8 , the extend of the cooling zone depends on the boiling regime. In the case of film boiling and transition, this cooling zone is observed downstream from the jet line $\left(x^{*}=0\right)$. This zone will be spread out on both sides of the axis of the jet, especially downstream from the jet in nucleate boiling. In forced convection regime, this zone will extend more upstream because of the influence of the hydraulic jump.

As a consequence of the motion of the wall, we cannot expect various boiling regime at the same time on the wall. When the wall is moving $(\omega \neq \mathbf{0} \mathbf{~ r a d} / \mathbf{s})$, we observed the homogenization of the boiling regimes over the cylinder wall in the "cooling zone". In the following section, local boiling curves which have been built as described in section 3.3 will be analysed.

\subsubsection{Boiling curves influenced by surface velocity and subcooling}

Local boiling curves are plotted on figure 9 for different points (in the reference frame of the jet). As we said in the previous section, at the beginning of the quenching experiment, the cooling zone is located downstream the centerline of the jet $\left(x^{*}=0\right)$; so, the boiling curves have been only built downstream the jet centerline $\left(x^{*}=0\right)$. For the set of data corresponding to the experimental conditions $\left(\Delta T_{s u b}=34 K ; u_{j}=1,06 \mathrm{~m} / \mathrm{s}-u^{*}=1,25\right)$, the maximum of CHF has been located at $x^{*}=$ 11.45. So on the figure 9, we compared the boiling curves of two pairs of symmetrical points located upstream and downstream the point where the maximum of CHF is located $\left(x^{*}=11.45\right)$. In what follows, we call the "upstream zone", the zone which is upstream the point where the maximum of CHF is located $\left(x^{*}=11.45\right)$ and "downstream zone", the zone which is downstream the point where the maximum of CHF is located $\left(x^{*}=11.45\right)$. 
In forced convection regime (figure 9a), heat flux values are slightly greater upstream of the point corresponding to the maximum of $\mathrm{CHF}\left(x^{*}=11.45\right)$. As the jet impinges a moving wall, the further we are of the jet axis $\left(x^{*}=0\right)$, the lower the heat transfer is. At the onset of nucleate boiling regime, we notice a homogenization of the heat flux and then for fully developed nucleate boiling regime, the heat flux is minimum in the beginning of the upstream zone and maximum in the downstream zone. In fact, in nucleate boiling, heat transfer is controlled by the dynamic of the bubble growth, detachment diameter and its frequency. It is well known that buyoancy and hydrodynamic forces control these phenomena. In the case of the rotating cylinder, bubbles growing at the wall move with it and thus, from a local point of view, the heat transfer increases from the upstream zone to the downstream zone (figure 9a).

CHF also depends on the curvilinear $x$-coordinate (figure 9b). It decreases more slightly beyond the MHF $\left(x^{*}=11.45\right)$. In transition boiling regime, we observed that the heat flux is greater for $x^{*}<11.45$ because the rewetting of the wall by fresh liquid must be more easy because of the shearing of the vapour columns (figure 9c). The Leidenfrost point $\left(T_{\text {lei. }}=260^{\circ} \mathrm{C}\right)$ has been determined by the comparison of the temperature's time evolution (figure 7) and the corresponding boiling curves. In film boiling(figure 9c), heat flux is still greater upstream the MHF and it decreases with the increase of curvilinear $x$-coordinate. A thicker vapour film should be formed by the vapour flowing within the wall motion.

\subsubsection{Effect of subcooling on the local boiling curves}

Subcooling moves the boiling curves towards greater fluxes and greater overheatings as it is shown on figure 10. We notice an increase of the heat flux in forced convection, a delay in the onset of boiling when subcooling increases, a weaker influence on the heat flux extracted in nucleate boiling (when subcooling increases). The Leidenfrost temperature corresponding at a minimum of heat flux 
between the film boiling regime and the transition boiling regime increases with subcooling. The various boiling curves are presented for a jet velocity of $1.06 \mathrm{~m} / \mathrm{s}$ or $u^{*}=1.25$.

A decrease of the heat flux on the entire boiling highlights he influence of the wall motion on the boiling curves (Figure 11). The influence of the wall motion in nucleate boiling regime is weaker than in the other regimes but CHF decreases strongly as the speed of the wall increases. Indeed the MHF point is located upstream the centreline of the jet (point where is located the maximum of $\mathrm{CHF}$ for the given $\mathrm{u}^{*}$ ratios). The more the speed of the wall increases, the more this point moves away from the centreline of the jet. CHF decreases also with the distance to the point of MHF. In other words the decrease will be much more significant when the speed of the wall will increase. In film boiling regime, the hydrodynamics of the jet probably modifies the vapour film thickness. The vapour film cannot being very stable for film boiling, as we observe strong fluctuations of heat flux in this regime, we suppose that some rewetting of the wall are involved. Indeed, these fluctuations are weaker when increasing the wall speed because the residence time of the fluid is decreasing.

\subsubsection{CHF influenced by surface velocity}

Local CHF values reported on figure 12 were estimated at a jet velocity of $1.06 \mathrm{~m} / \mathrm{s}$, a subcooling of $50 \mathrm{~K}$ and different surface velocities (ie different velocity ratio $u^{*}$ ). The maximum of $\mathrm{CHF}$ decreases as the velocity surface increases. Moreover, the MHF is shift to higher values of $x^{*}$ as $u^{*}$ increases. This indicates that the speed ratio is one of the most important parameter involving in boiling heat transfer of jet impinging a moving surface.

\section{Concluding remarks}

The study of jet cooling on a moving surface presents much interest insofar as the studies carried out in this field do not take into account the boiling phenomena on moving surfaces and do not describe the entire boiling curve. So, the goal of this study was to estimate local boiling curves for a 
moving surface. First, we have designed an experimental device which simulates the cooling of hot moving products. So, we chose a rotating cylinder which allows an enough long time of experimentation to be able to describe the entire boiling curve.

In the case of static surface, part of our study have consisted with the validation of the experimental device. For that purpose, we made some comparison with another studies. The boiling curves measured beneath the impact of the jet present a characteristic shoulder of flux whose width (in term of overheating) increases with subcooling. In the parallel flow region, the boiling curves are classical. Our results are quite consistant with previous studies [1,5].

Heat transfer is radically modified when the impingement surface is moving. The first effect is a homogenization of the local boiling curves. We do not observed a "shoulder of flux" beneath the jet axis and the local boiling curves have the same shape upstream, downstream and beneath the centreline of the jet. Thus the temperature of the onset of boiling and the rewetting temperature (Leidenfrost point) remain quite independent of the $\mathrm{x}$-coordinate in the cooling zone. The Leidenfrost point depends only on subcooling. It varies between $260^{\circ} \mathrm{C}$ and $290^{\circ} \mathrm{C}$ for a range of subcooling lying between 18 and 34K. The second effect is the decrease of the CHF. The maximum of CHF is lower than in the static case. The Leidenfrost temperature decreases so film boiling is observed with less significant overheatings compared to the static case. The last effect is related to the cooling zone. At the beginning of cooling, the cooling zone begins beneath the jet and is developing only downstream. Moreover, the maximum of heat transfer is not located beneath the jet and it moves during the cooling. A dissymmetry of the heat transfer is also observed upstream and downstream the maximum of heat transfer. It is a consequence of the interaction between the jet on the moving surface of the cylinder, specially when counter-current appears (upstream), which induces a strong evolution of the flow field. 


\section{References}

[1] Ishigai S., Nakanishi A. and Ochi T., 1978, Boiling heat transfer for a plane water jet impinging on a hot surface, 6th International Heat transfer Conference, 1, FB 30, 445-450.

[2] Ochi T., Nakanishi S., Kaji M., Ishigai S., 1984, Multi-phase and Heat Transfer III. Part A : Fundamentals - Cooling of a hot plate with an impinging circular water jet, Elsevier Science Publishers B.V., Amsterdam, 671-681.

[3] Hall E. D., Incropera F. P., Viskanta R. : Jet impingement boiling from a circular free-surface jet during quenching : Part1 - single-phase jet, J. of Heat transfer, Vol. 123, pp. 901-910, 2001.

[4] Wolf, D.H., 1993, Turbulent development in a free surface jet and impingement boiling heat transfer, Ph. D., Purdue University.

[5] Robidou H., Auracher H., Gardin, P. and Lebouché M., 2002, Controlled cooling of a hot plate with a water jet, Experimental Thermal and Fluid Science, 26, Issues 2-4, June 2002, 123-129

[6] Seiler N, Seiler J.M. and Simonin O., 2004, Transition boiling at jet impingement, Int. Journal of Heat and Mass Transfer, 47, Issue 23, 5059-5070

[7] Watson, E.J., 1964, The radial spread of a liquid jet over a horizontal plane, J. Fluid Mech., 20, $481-495$.

[8] A. Kouachi, 2006, Etude expérimentale de l'ébullition convective d'un jet d'eau plan impactant une surface mobile portée à hautes temperatures, $\mathrm{PhD}$ thesis, University Henri Poincaré.

[9] F. Volle, 2006, Conduction inverse sur un cylindre en rotation - Cas de l'ébullition convective induite par l'impact d'un jet d'eau, PhD thesis, University Henri Poincaré.

[10] Volle F., Maillet D., Gradeck M., Lebouché M., 2007, Semi-analytical inverse heat conduction on a rotating cylinder with Laplace and Fourier transforms, Inverse Problems in Science and Engineering, to be published.

[11] Maillet D., André S., Batsale J.C, Degiovanni A. and Moyne C., 2000, Thermal quadrupoles : solving the heat equation through integral transforms, John Wiley and Sons, UK. 
[12] Maillet D., Degiovanni A. and André S., 1996, Estimation of a space varying heat transfer coefficient or interface resistance by inverse conduction, proceedings of the $23^{\text {rd }}$ International Conference on Thermal Conductivity, Tecnomic Pub. Co, Lancaster, Pennsylvania, 72-84.

[13] Beck, J.V., Blackwell, B., St Clair, C.R., 1985, Inverse Heat Conduction : Ill-posed Problems, (Wiley), New-york, USA.

[14] Blanc G., Raynaud M., Chau T. H., 1998, A guide for the use of function specification method for 2D inverse heat conduction problems, Revue Générale de Thermique, Vol. 37, 17-30.

[15] Aloke Kumar Mozumder, Masanori Monde, Peter Lloyd Woodfield and Md. Ashraful Islam, 2006, Maximum heat flux in relation to quenching of a high temperature surface with liquid jet impingement, Int. Journal of Heat and Mass Transfer, Volume 49, Issues 17-18, Pages 2877-2888 [16] Miyasaka, Y., Inada, S. and Owase, Y., 1980, Critical heat flux and subcooled nucleate boiling in transient region between a two-dimensional water jet and a heated surface, J. Chem. Eng. Japan, $13,29-35$

[17] M. Gradeck, A. Kouachi, A. Dani, D. Arnoult and J.L. Boréan, 2006, Experimental and numerical study of the hydraulic jump of an impinging jet on a moving surface, Experimental Thermal and Fluid Science, 30, 193-201.

[18] M. Gradeck, A. Kouachi, J.L. Borean, P. Gardin, M. Lebouché, Cooling of a hot cylinder with an impinging planar water jet, International Heat Transfer Conference, Sydney 2006, ISBN 156700-225-0/CD1-56700-226-9 


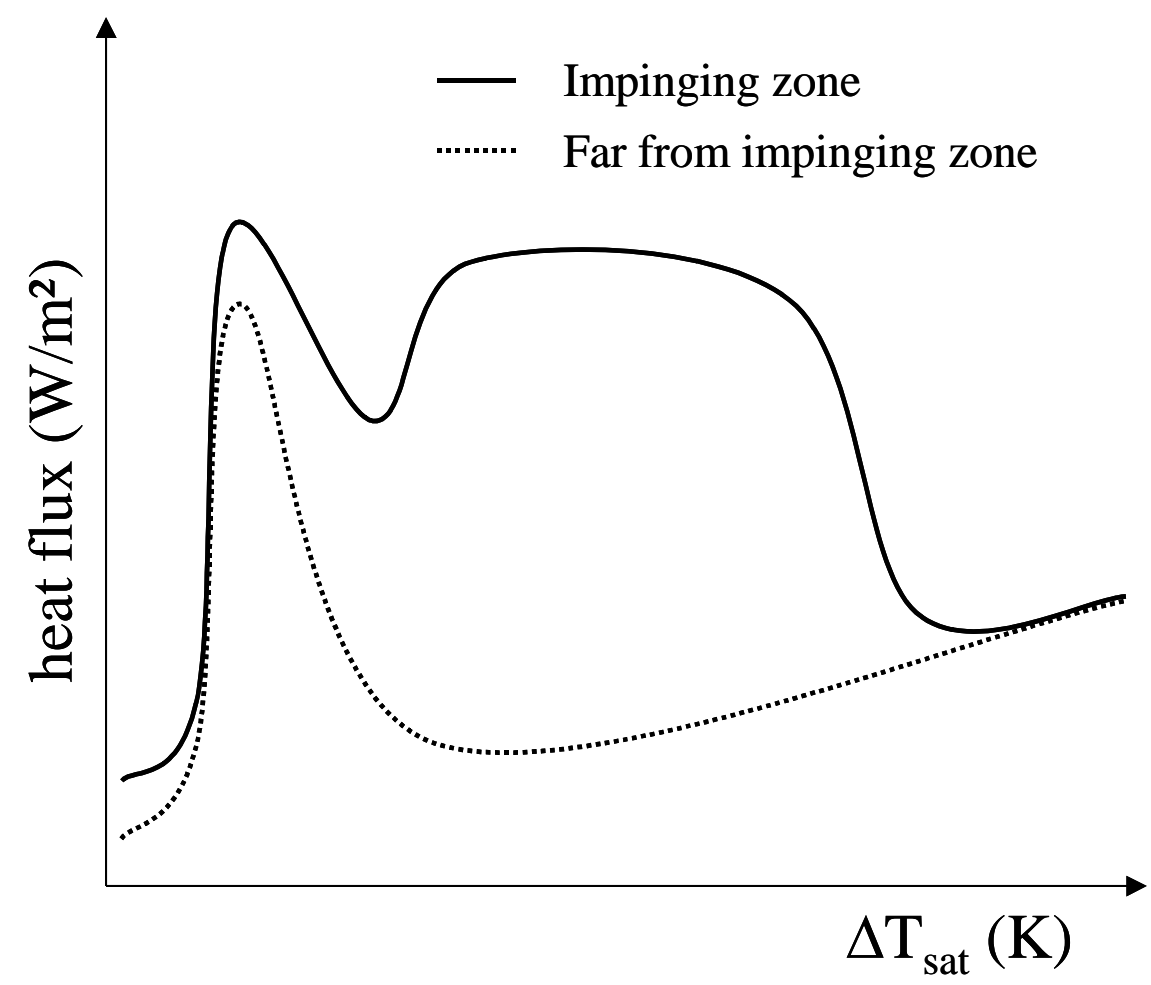

Figure 1 : Shape of the boiling curve in impinging jet experiments 

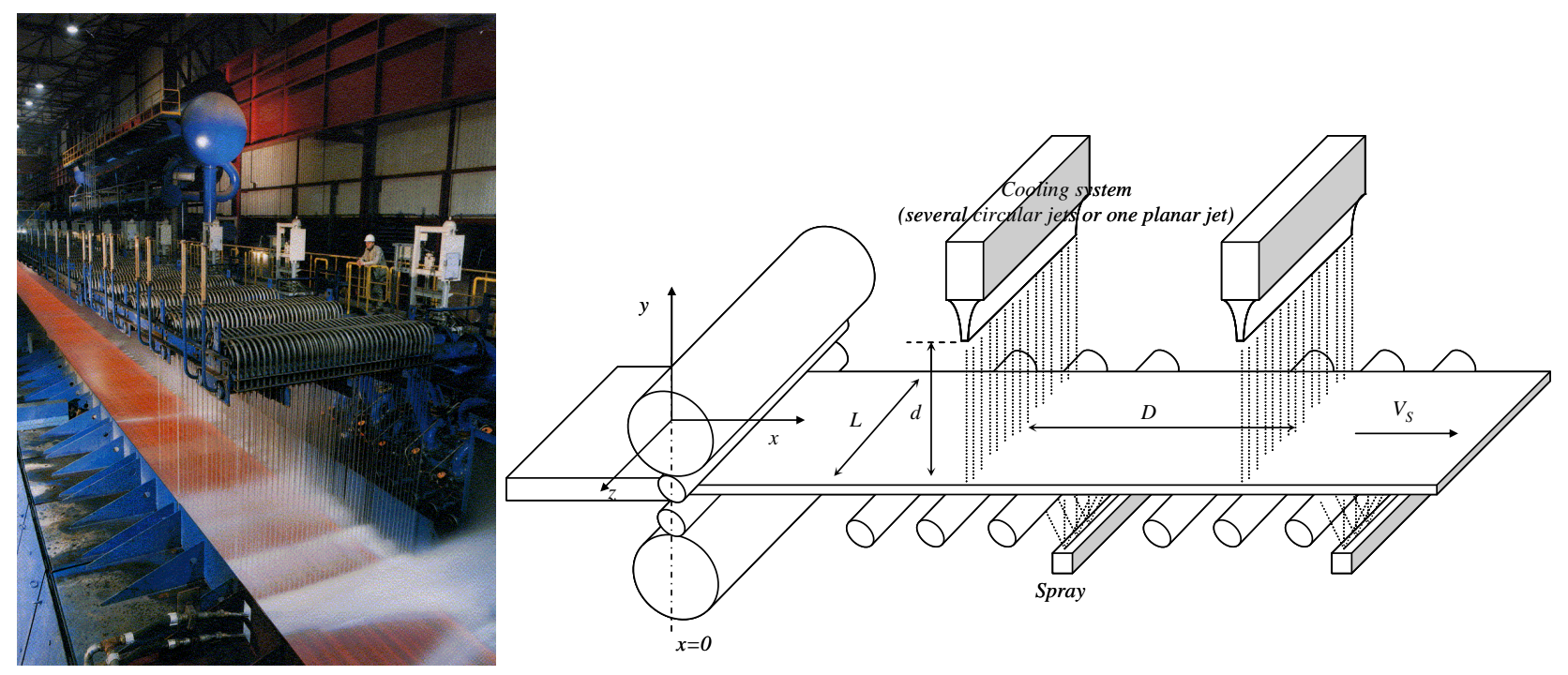

Figure 2 : picture and schematic of a real cooling system 


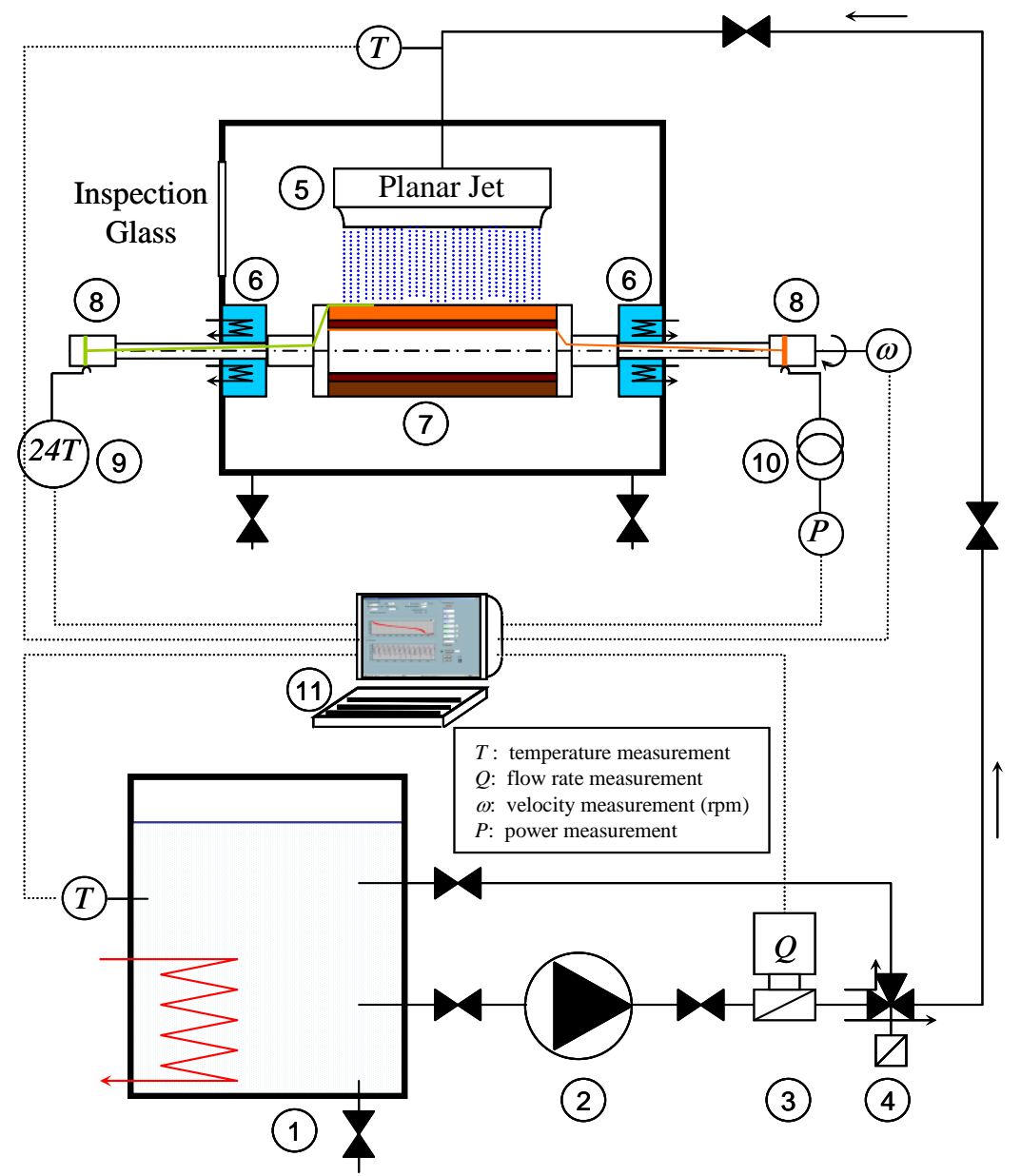

Figure 3 : Schematic of the experimental set-up 
Stagnation zone, $x^{*}=0$

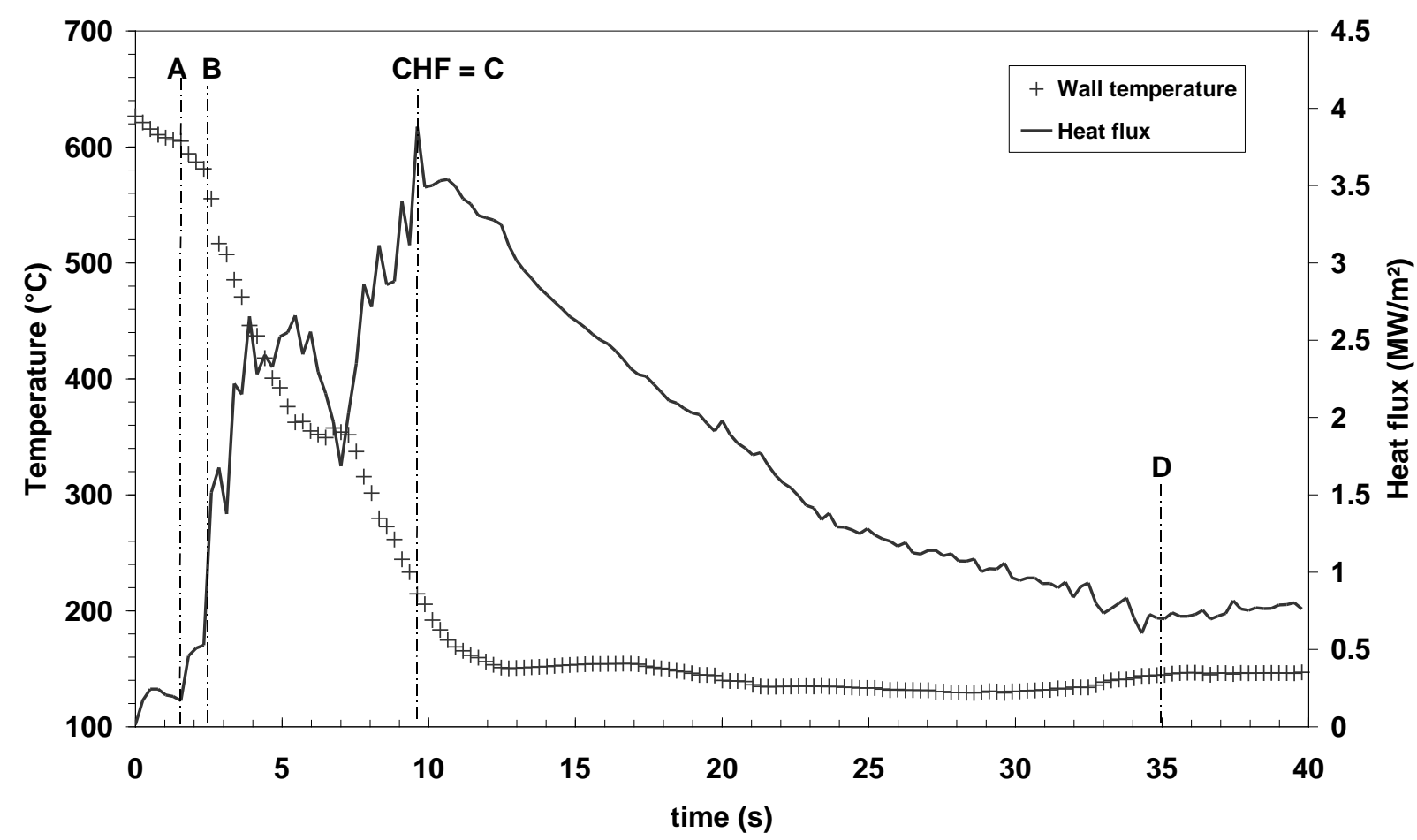

parallel flow zone, $x^{*}=9.15$

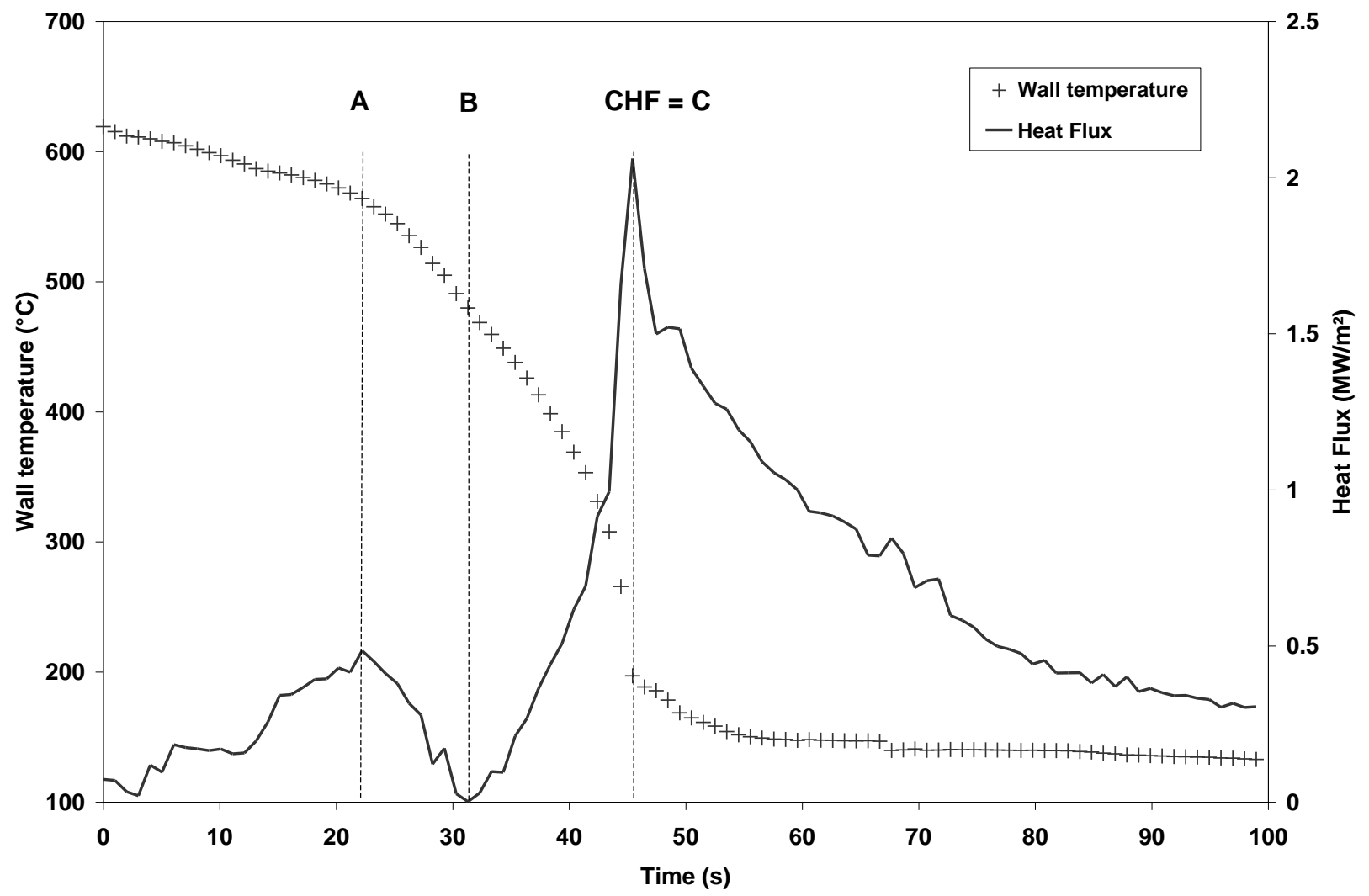

Figure 4 : Example of temperature and wall heat flux evolutions $\omega=0-\Delta T_{\text {sub }}=15 \mathrm{~K}-u_{j}=1.2 \mathrm{~m} / \mathrm{s}-d=50 \mathrm{~mm}$ 


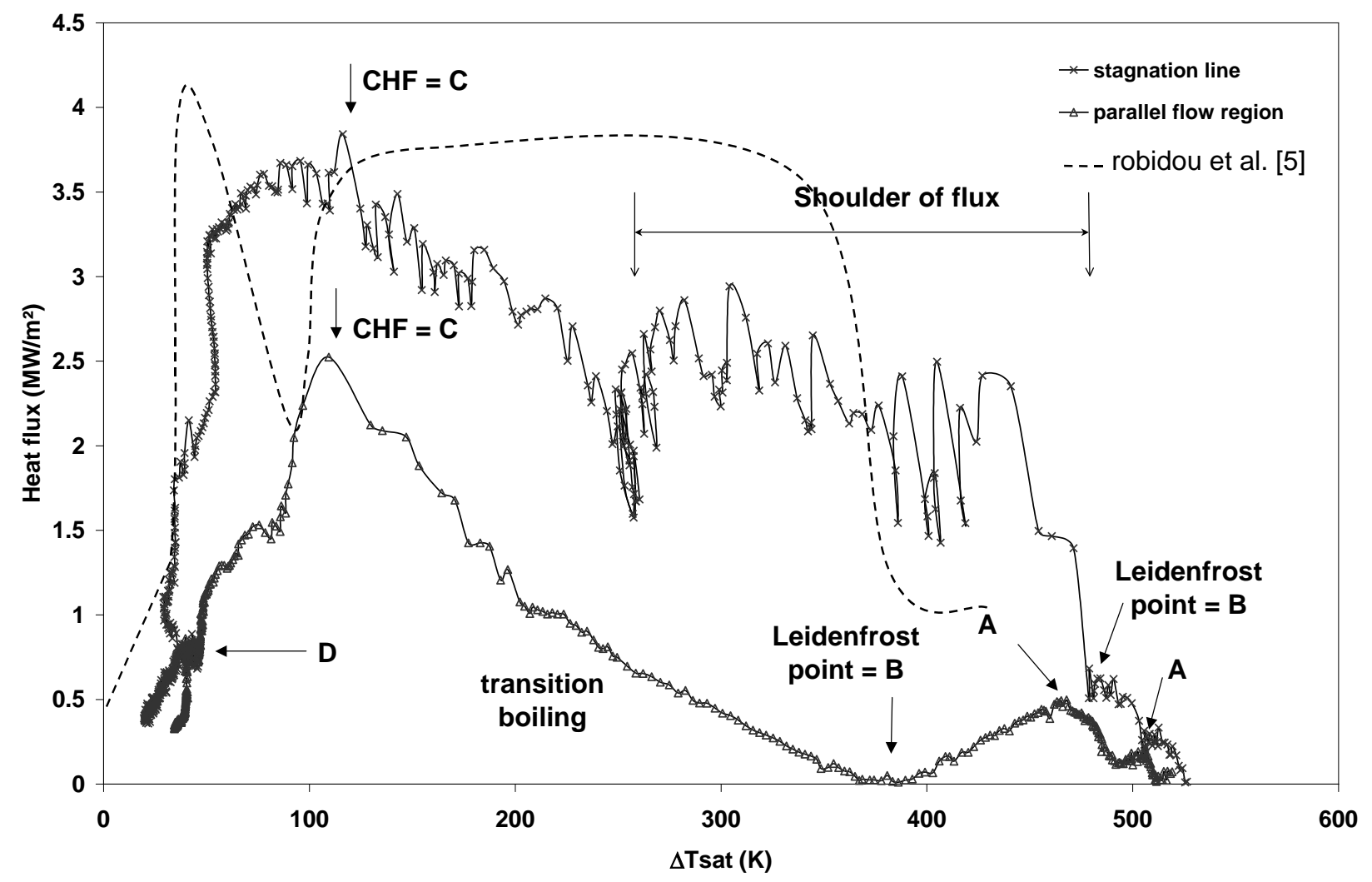

Figure 5 : Example of boiling curves from temperature measurements and estimated heat flux $\omega=0-\Delta T_{\text {sub }}=15 \mathrm{~K}-u_{j}=1.2 \mathrm{~m} / \mathrm{s}-d=50 \mathrm{~mm}$ 


\begin{tabular}{|c|c|c|c|c|c|}
\cline { 2 - 6 } \multicolumn{1}{c|}{} & $T\left({ }^{\circ} \mathrm{C}\right)$ & $\sigma(\mathrm{N} / \mathrm{m})$ & $C_{P}(\mathrm{~J} / \mathrm{kg} \cdot \mathrm{K})$ & $\rho(\mathrm{kg} / \mathrm{m} 3)$ & $h(\mathrm{~kJ} / \mathrm{kg})$ \\
\hline water & 85 & $0.0589\left(T=100^{\circ} \mathrm{C}\right)$ & 4202.5 & 968.56 & $419,1 \quad\left(T=100^{\circ} \mathrm{C}\right)$ \\
\hline & 75 & & 4193 & 974.84 & \\
\hline & 66 & & 4187 & 980.55 & \\
\hline steam & 100 & & & 0.5896 & 2676 \\
\hline
\end{tabular}

Table 1: Thermophysical properties of water and steam $(\mathrm{p}=1$ bar) 

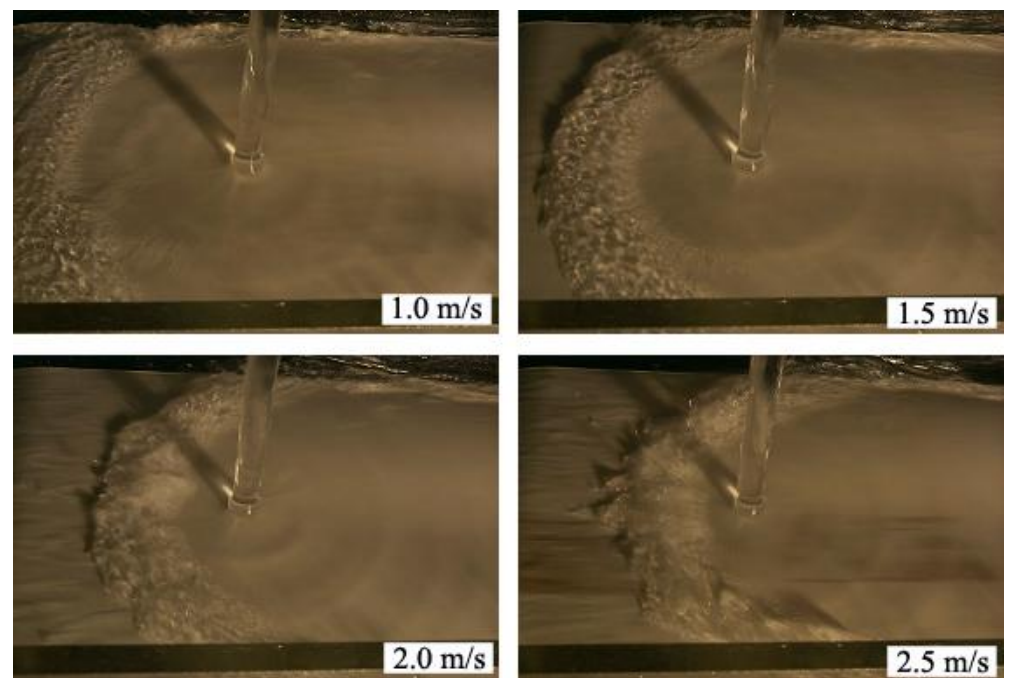

Figure 6 : hydraulic jump visualizations for different surface velocities $-u_{j}=1.4 \mathrm{~m} / \mathrm{s}$ From Gradeck et al. [17] 
Titre:
D:ligradeck AARTCLElarticle Kouachilf igure 7.eps
Awer:

Auteur:

Aperçu:

av ec un aperçu intégré.

Cette image EPS peut être imprimée sur

imprimante Postscript mas pas sur
un autre ty pe dimprimante.

figure 7: example of time evolution of the temperature

$\Delta T_{\text {sub }}=34 \mathrm{~K}-u^{*}=1.25-d=50 \mathrm{~mm}$ 


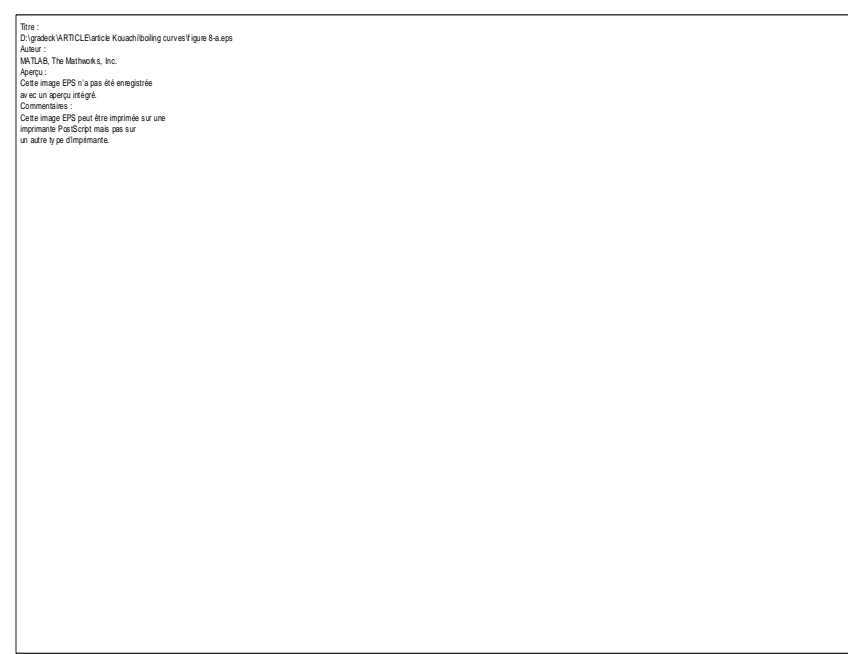

(a) quenching time

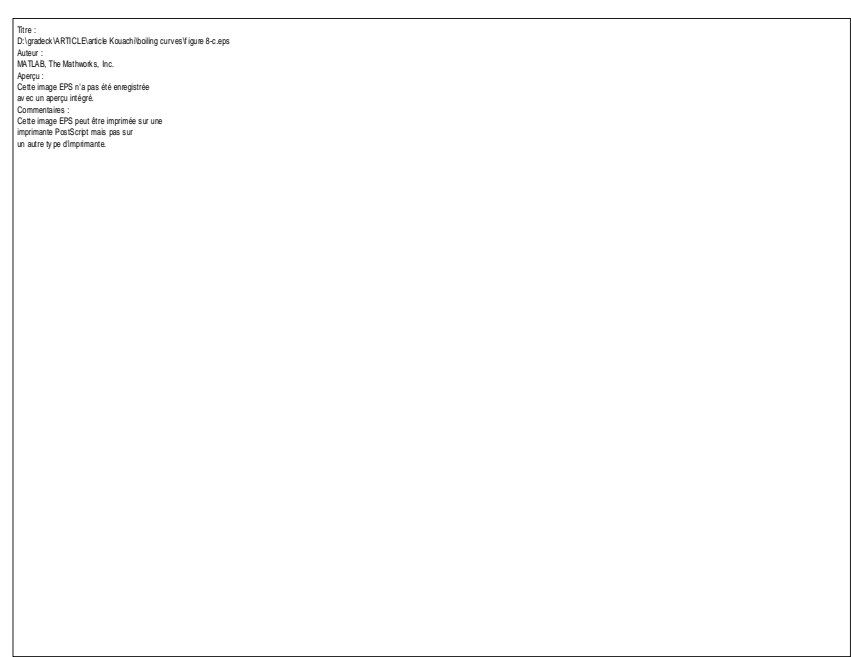

(c) transition boiling

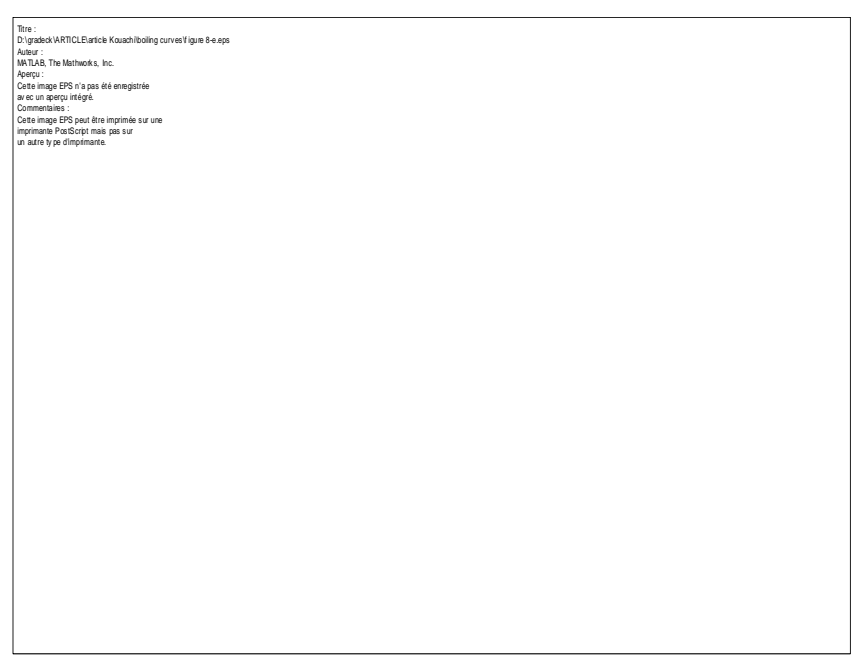

(e) forced convection

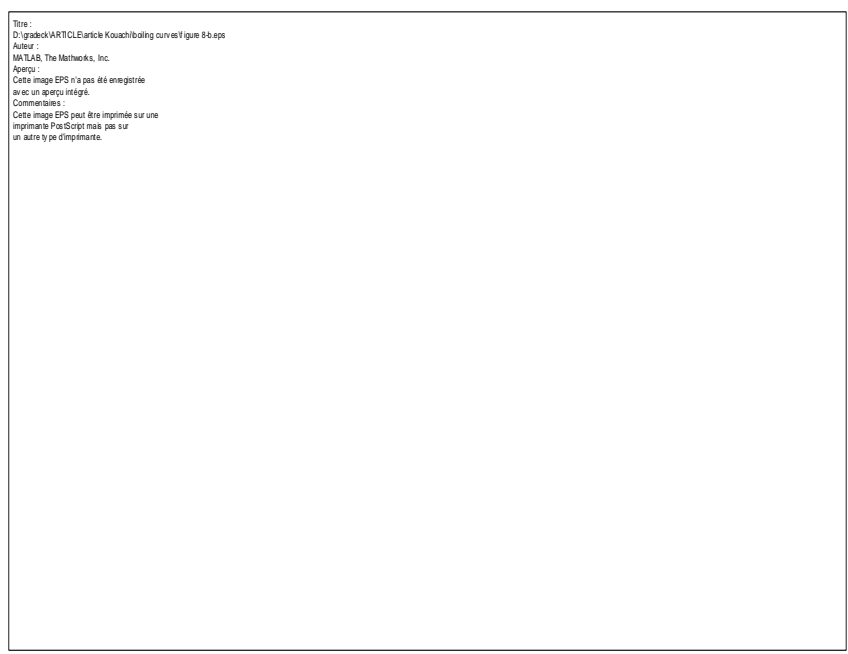

(b) film boiling

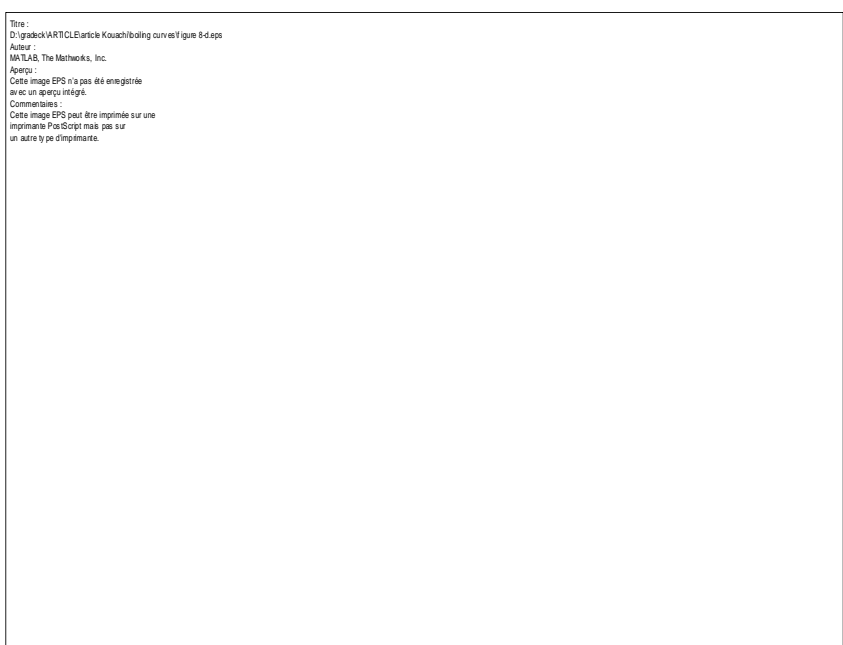

(d) nucleate boiling

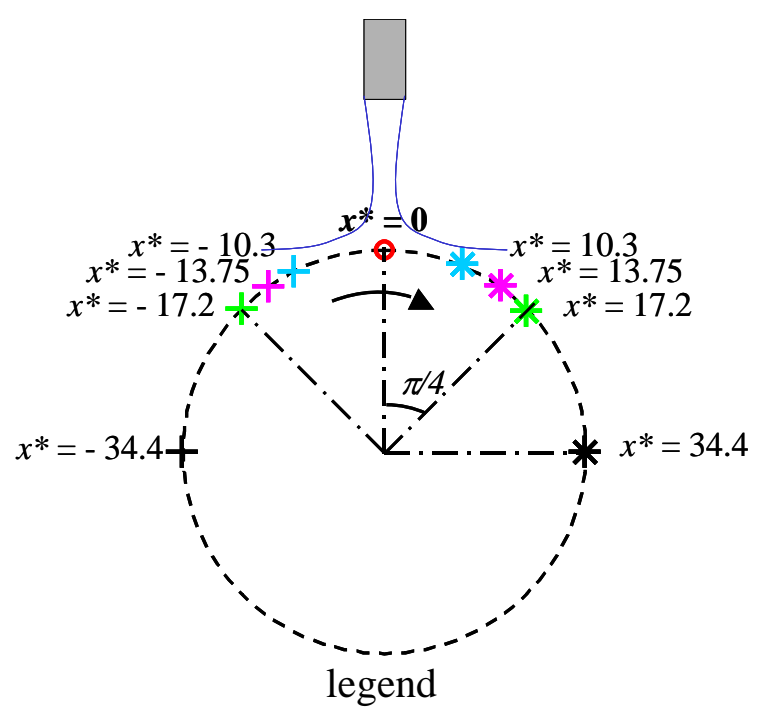

Figure 8: Cooling curve, $\Delta T_{\text {sub }}=34 K ; u_{j}=1,06 \mathrm{~m} / \mathrm{s}-u^{*}=1,25$ 


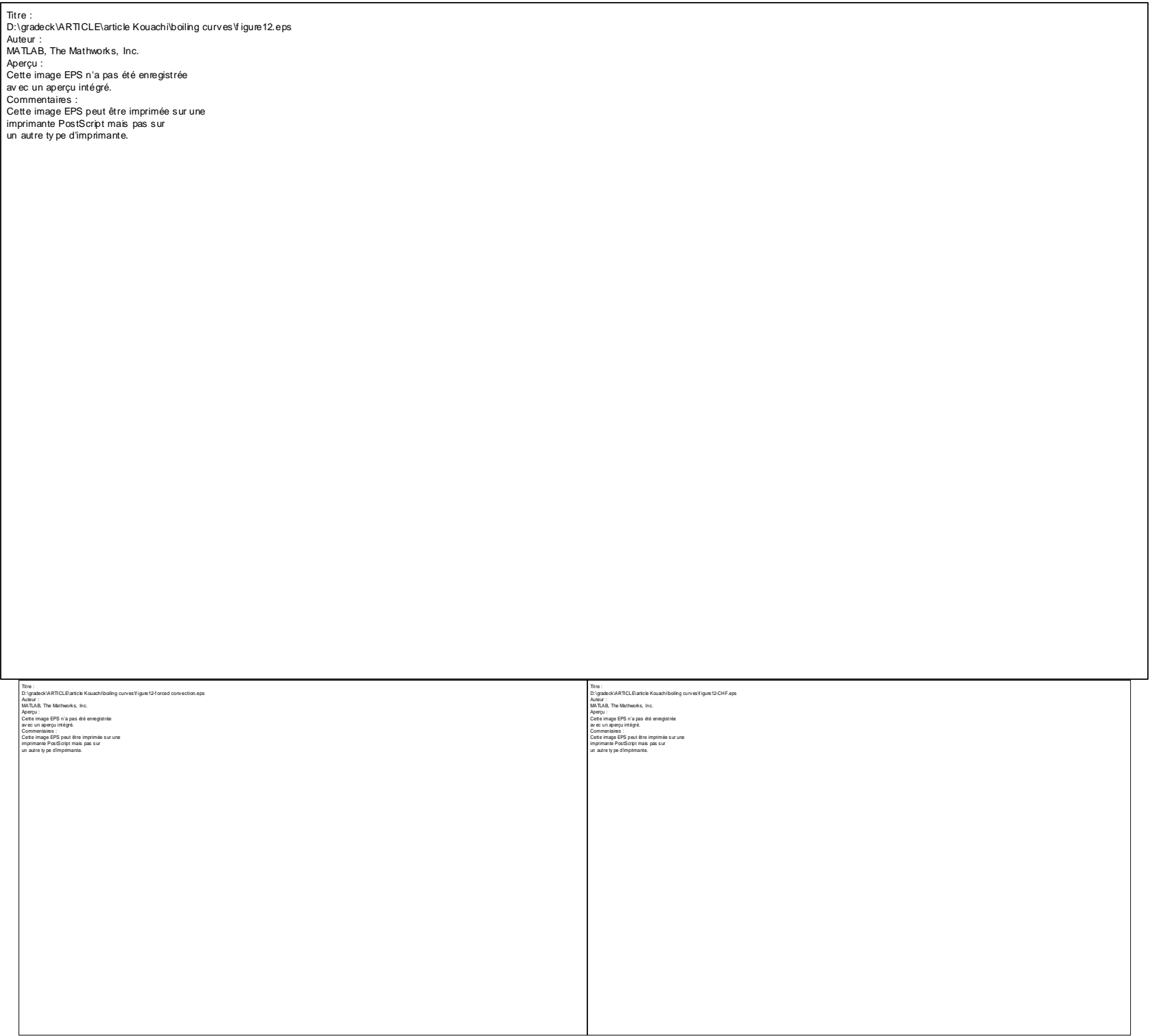

(a)

(b)

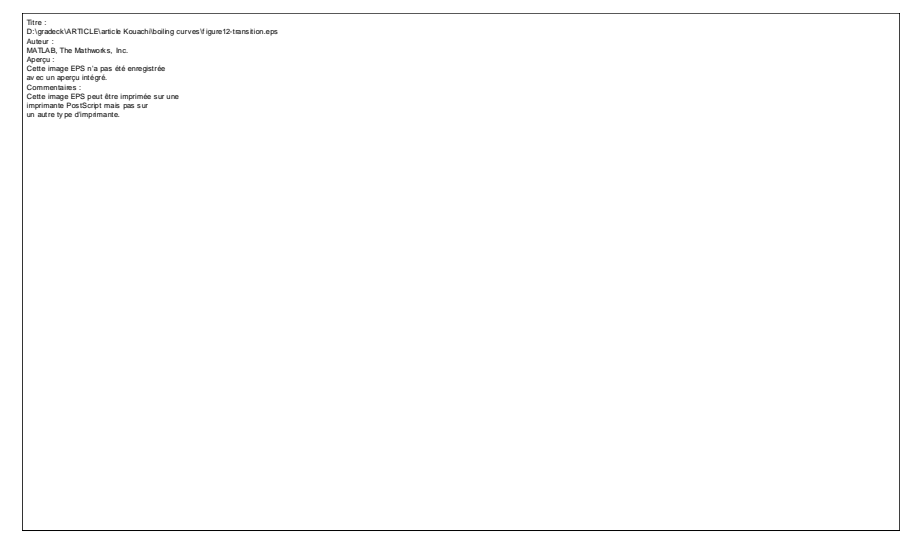

(c)

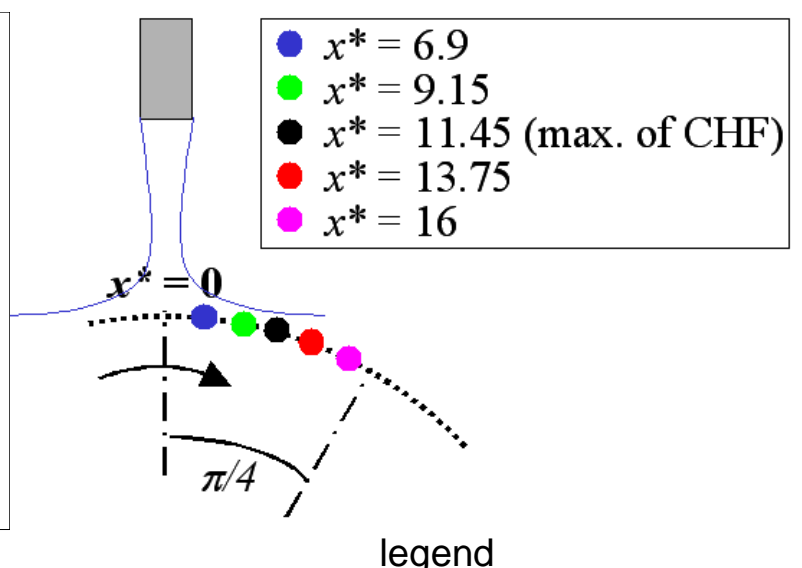

Figure 9 : local boiling curves, $\Delta T_{\text {sub }}=34 \mathrm{~K} ; u_{j}=1,06 \mathrm{~m} / \mathrm{s}-u^{*}=1,25$ 


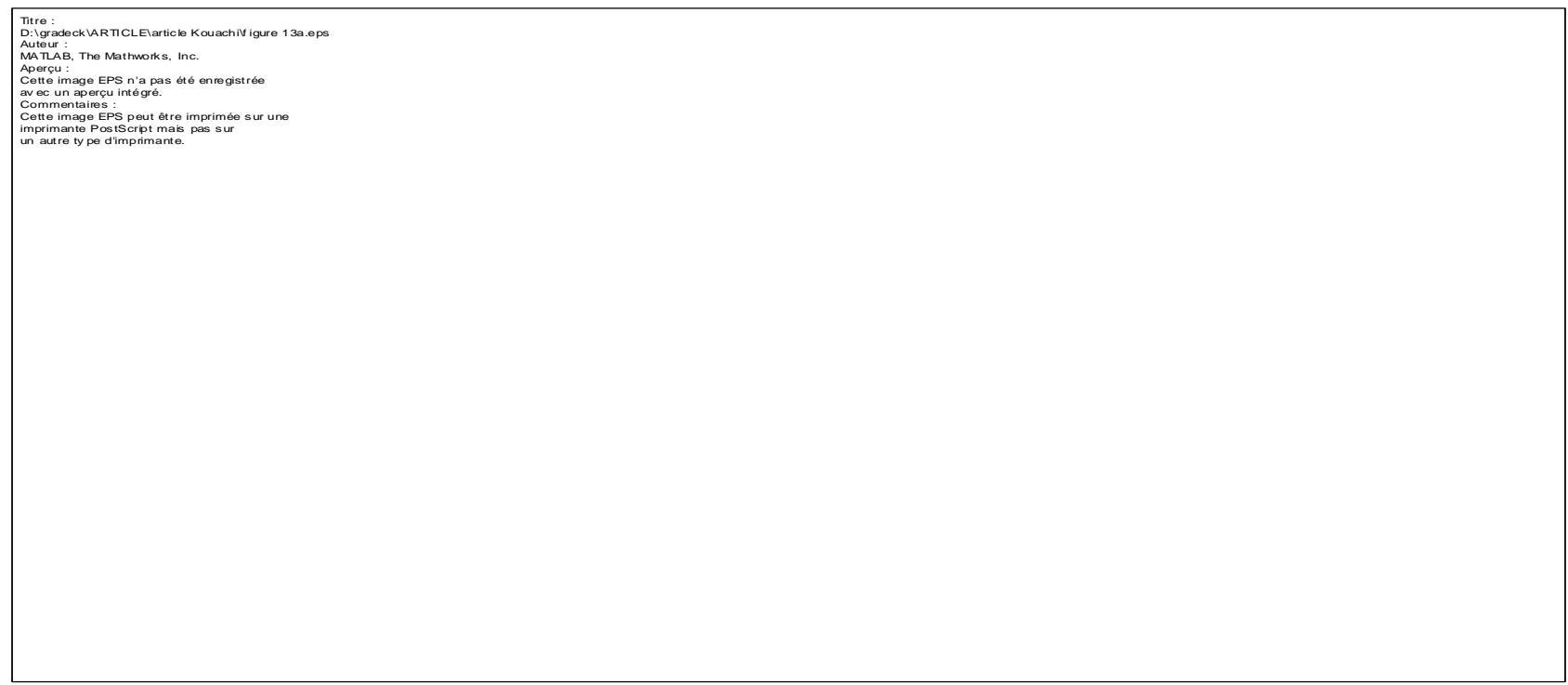

Figure 10a : Influence of subcooling: $x^{*}=0$ (center line of jet), $u_{j}=1,06 \mathrm{~m} / \mathrm{s} ; u^{*}=1,25$

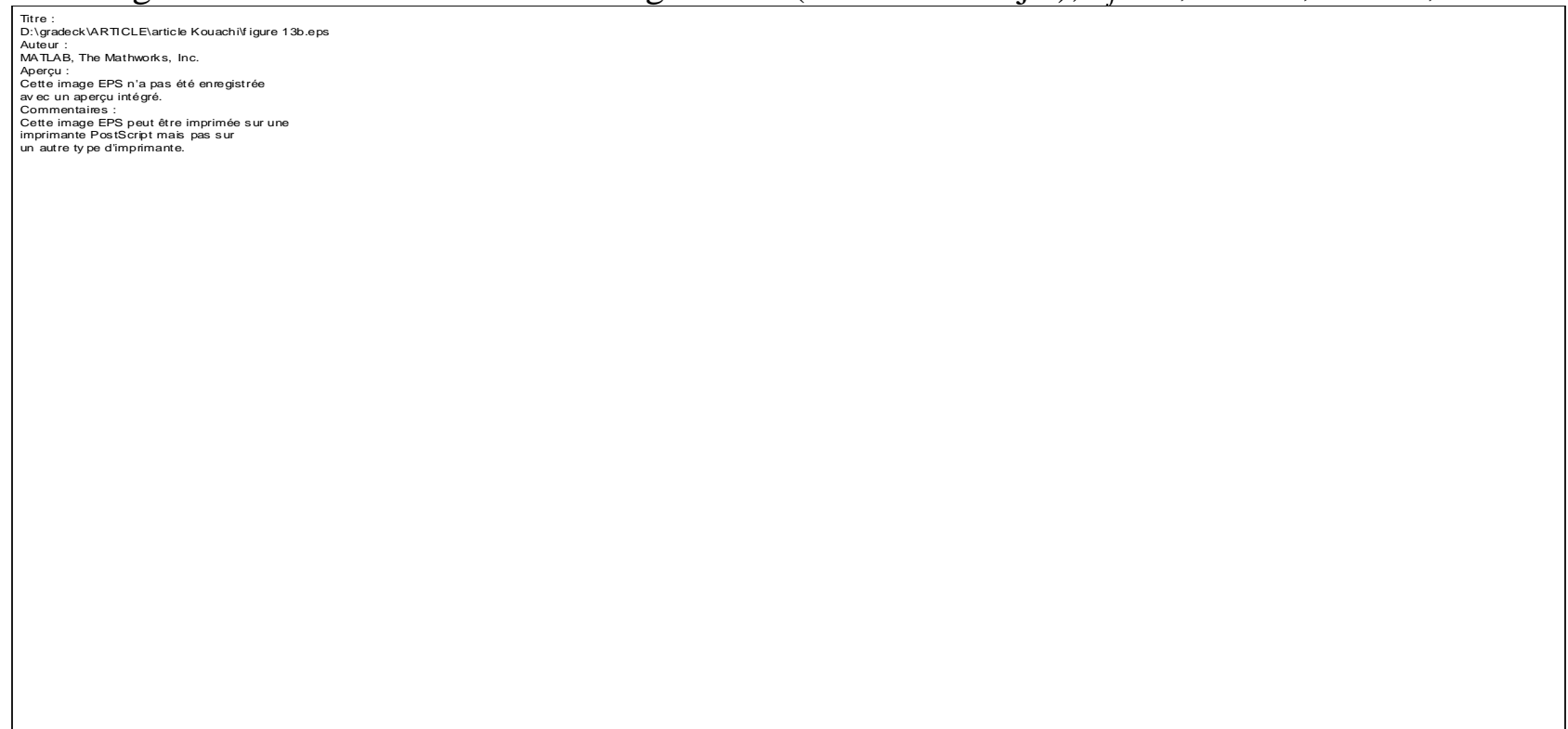

Figure 10b : Influence of subcooling: $x^{*}=11.45 ; u_{j}=1,06 \mathrm{~m} / \mathrm{s} ; u^{*}=1,25$

\section{Titre:
D: Ilgradeck iARTCLElarticle Kouachilf igure $13 c$.eps
Auteur}

MATAB, The Mathworks, Inc

Aperç:
Cette image EPS n'a pas été enregistrée
av ec un aperçu intégré.

Commentaires:

imprimante Postscript têtre imprimée sur une

in autre ty pe dimprimante.

Figure 10c : Influence of subcooling: $x^{*}=16 ; u_{j}=1,06 \mathrm{~m} / \mathrm{s} ; u^{*}=1,25$ 
Titre:
D:lgradeck $A R T C L E$ larticle Kouachiff igure 14.eps
Auter:

Auteur:

Aperçu:
Cette image EPS n'a pas été enregistrée

av ec un aperçu intégré.

Cette image EPS peut être imprimée sur une

un autre ty pe dimprimante.
intion

Figure $11:$ Influence of the wall speed at the centreline of the jet, $u_{j}=1,06 \mathrm{~m} / \mathrm{s}, \Delta T_{\text {sub }}=18 \mathrm{~K}$. 


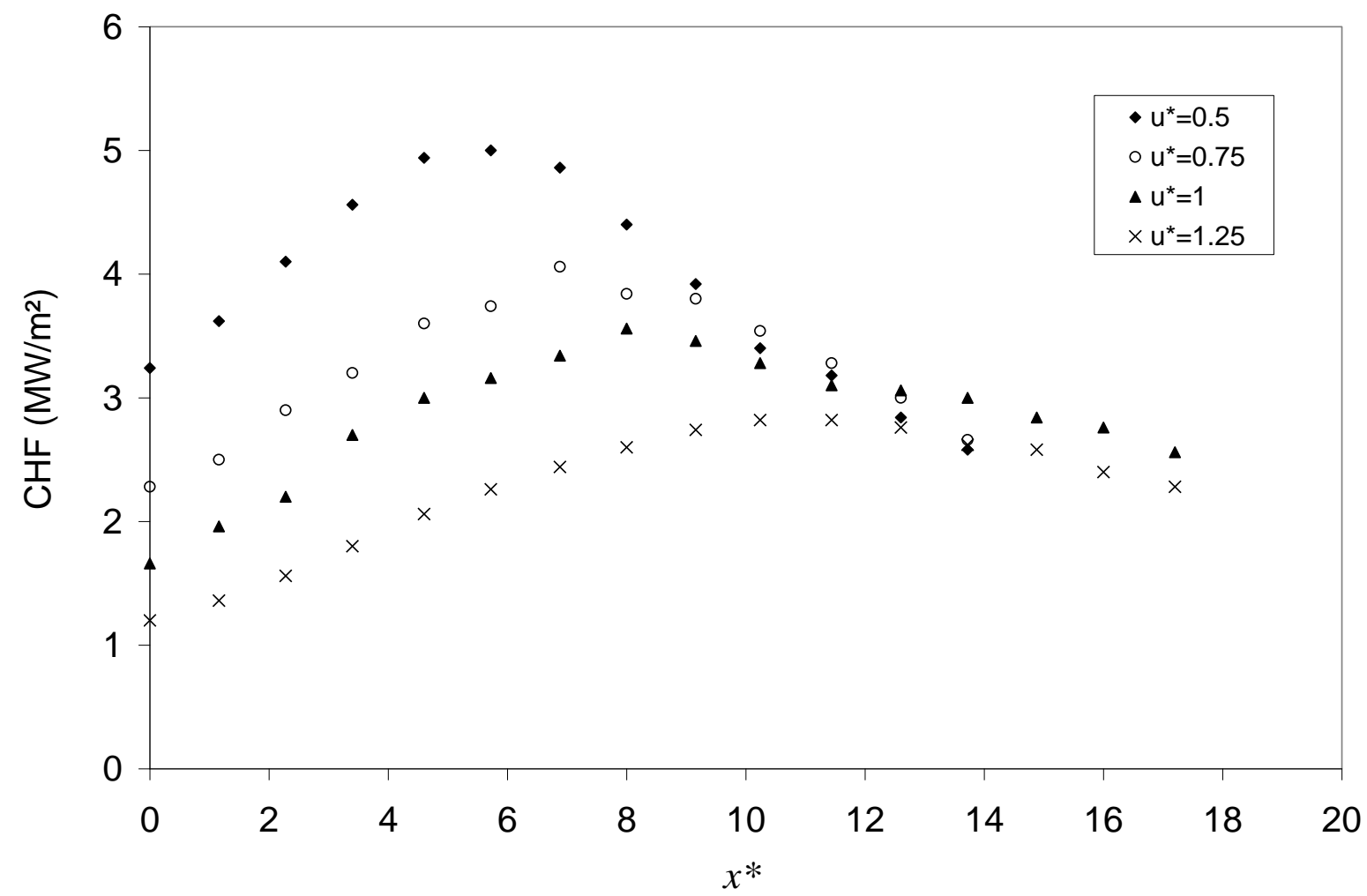

Figure 12: Influence of the wall speed on the local CHF, $u_{j}=1,06 \mathrm{~m} / \mathrm{s}, \Delta T_{\text {sub }}=50 \mathrm{~K}$. 